\title{
Acción de la miotoxina del veneno de Bothrops brazili Hoge, 1953 (Ophidia: Viperidae)*
}

\section{Action of the myotoxin from Bothrops brazili Hoge, 1953 snake venom (Ophidia: Viperidae)}

\author{
Carmen Pantigoso ${ }^{1}$, Enrique Escobar ${ }^{2}$ y Armando Yarlequé ${ }^{1}$
}

\begin{abstract}
Resumen
Se ha estudiado el modo de acción de la miotoxina aislada del veneno de la serpiente Bothrops brazili. La inoculación de la miotoxina en el músculo gastrocnemius de ratones albinos produce durante la primera hora de acción la liberación de creatina kinasa y lactato deshidrogenasa, mientras que por PAGE-SDS, se revela que la incubación de la miotoxina con músculo gastrocnemius aislado, produce además la liberación de otras proteínas musculares.
\end{abstract}

Asimismo, la miotoxina produce hipercontracción, lesiones delta e incrementa los niveles de calcio intramuscular, tanto in vivo como in vitro, lo cual no depende del ingreso de calcio extracelular vía receptores de dihidropiridina. Este incremento de calcio explicaría la hipercontracción observada y podría generar la activación de proteasas y lipasas endógenas dependientes de calcio, que conducirían a la necrosis muscular.

Palabras clave: miotoxina, Bothrops brazili, veneno de serpiente, mionecrosis

\section{Abstract}

The myotoxin isolated from the venom of the snake Bothrops brazili has been studied in its mode of action. In the first hour of activity the myotoxin injected in the gastrocnemius muscle of white mice, induces the release of creatine kinase and lactate dehydrogenase, while by PAGE-SDS, it is shown that the incubation of miotoxin with isolated gastrocnemius muscle releases other proteins from this tissue.

Moreover myotoxin produces hipercontraction, delta lesions and increases the concentration of intramuscular calcium "in vivo" and "in vitro", which does not depend on extracellular calcium entry through dyhidropyridine receptors. This increase of calcium would explain the hipercontraction observed. Also it could trigger the activation of endogenous proteases and lipases, which would lead to muscle necrosis.

Keywords: myotoxin, Bothrops brazili, snake venom, myonecrosis

\section{Introducción}

En nuestro país la mayoría de serpientes venenosas pertenecen a la Familia Viperidae, siendo el género Bothrops, el más abundante y el responsable de la mayoría de accidentes ofídicos. Los venenos de estas serpientes producen, entre otros efectos, una severa necrosis

${ }^{1}$ Laboratorio de Biología Molecular. Facultad de Ciencias Biológicas. UNMSM.

${ }^{2}$ Laboratorio de Bioquímica y Genética

Molecular. Facultad de Ciencias Biológicas.

UNMSM. eescobarg@unmsm.edu.pe

* Proyecto financiado por el FEDU, CSI:

001001141 del tejido muscular (mionecrosis) (Rosenfeld, 1971). En el caso de la familia Elapidae, sólo el veneno del grupo de las cobras produce también mionecrosis pero ésta es menos intensa que la ocasionada por los vipéridos.

Por mucho tiempo se creyó que la necrosis producida por algunos venenos de serpientes se debía a la acción de enzimas proteolíticas presentes en el veneno (Houssay, 1930; Kellaway, 1939; Zeller, 1948; Porges, 1953; Kaiser and Michl, 1958). Sin embargo, una observación contraria a esta creencia fue establecida cuando se encontró que los venenos de cobras de la península malaya eran capaces de producir necrosis, pese a no ser 
proteolíticos (Reid, 1964); y, en cambio, los venenos de Trimeresurus okinavensis (Kurashigue et al., 1966) Bitis gabonica, B. nasicornis y B. arietans (Tu et al., 1969) producían débil mionecrosis, pese a ser proteolíticos.

Paralelamente fue posible inducir mionecrosis con fosfolipasa A de Trimeresurus flavoviridis (Maeno et al., 1962; Sarkar and Devi, 1968), lo cual permitió atribuir el efecto necrótico a la actividad de fosfolipasa. Sin embargo, en 1966, Kurashigue purificó del mismo veneno factores miolíticos sin actividad de fosfolipasa.

En 1976, Ownby et al. aislaron una miotoxina de Crotalus viridis viridis que no tenía actividad enzimática, y que fue denominada miotoxina $a$; ésta fue la primera miotoxina bien caracterizada. Posteriormente, en 1984, se aisló del veneno de Bothrops asper una miotoxina que tenía actividad de fosfolipasa (Gutiérrez et al., 1984), mientras que algunos años después se reportaron en los venenos de $B$. nummifer y $B$. jararacussu, dos nuevas miotoxinas pero ambas sin actividad enzimática (Gutiérrez et al., 1986; HomsiBrandeburgo et al., 1988).

A la fecha, y luego de una considerable información acumulada, se sabe que las miotoxinas de venenos de serpientes son proteínas básicas que se clasifican en 3 grupos (Ownby, 1998):

1.Miotoxinas relacionadas a las fosfolipasas, las cuales poseen aproximadamente 135 aminoácidos, y son características de la familia Viperidae, especialmente del género Bothrops. La elevada frecuencia en nuestro país de especies del género Bothrops determinan que este grupo resulte de especial interés.

2. Miotoxinas de bajo peso molecular, que se caracterizan por tener 42 aminoácidos y carecer de actividad enzimática. Son características de los venenos de serpientes del género Crotalus, tales como $C$. viridis viridis, C. durissus terrificus y C. adamanteus.
3. Miotoxinas de las cobras, las cuales son denominadas cardiotoxinas, ya que actúan preferentemente sobre el músculo cardíaco. Estas proteínas poseen alrededor de 60 aminoácidos.

Adicionalmente, se ha establecido que las miotoxinas del primer grupo pueden ser de dos tipos: unas con actividad de fosfolipasa (tienen Asp en la posición 49) y otras sin actividad enzimática (tienen Lys en la misma posición) (Gutiérrez and Lomonte, 1997; Ownby et al., 1999).

En relación al mecanismo de acción se ha postulado que estas toxinas actúan sobre la membrana de células musculares, aunque el lugar exacto de unión es desconocido. Algunos datos estructurales y farmacológicos sugieren la presencia en la miotoxina, de un dominio para el daño de la membrana, probablemente formado por la combinación de residuos básicos e hidrofóbicos (Gutiérrez et al., 1989; Volpe et al., 1986; Yudkowsky, et al., 1994). Gutiérrez et al. (1984) también refieren que la miotoxina de $B$. asper afecta la integridad de la membrana plasmática, ya que induce un rápido incremento en el plasma de los niveles de creatina kinasa, y produce además una elevación de la concentración de calcio citosólico. Sin embargo, el mecanismo que conduce a la pérdida del control de la regulación del ion calcio es un aspecto aún desconocido.

En este trabajo, hemos estudiado el mecanismo de acción de la miotoxina del veneno de Bothrops brazili, cuyo aislamiento y propiedades fueron presentados por nosotros en un trabajo anterior (Pantigoso et al., 2001).

\section{Material y métodos}

\section{Miotoxina}

Se utilizó la miotoxina aislada del veneno de la serpiente Bothrops brazili, de acuerdo al método de Pantigoso et al. (2001).

\section{Cuantificación de proteína}

En todos los ensayos el contenido proteico se determinó por el método de Lowry (1951), 
que usó como proteína estándar albúmina bovina $0,1 \mathrm{mg} / \mathrm{ml}$.

\section{Electroforesis en gel de poliacrilamida con dodecil sulfato de sodio (PAGE-SDS)}

Los diferentes ensayos de PAGE-SDS se hicieron de acuerdo al método de Laemmli (1970), que empleó un gel de stacking al 4\% y un gel de resolución al 7,5\%. Las proteínas fueron teñidas con azul brillante de coomassie $0,2 \%$ durante 5 minutos y decoloradas en una solución acuosa conteniendo metanol $24 \%$ y ácido acético $8 \%$.

\section{Acción de la miotoxina}

Se evaluó a través de los siguientes ensayos:

\subsection{Liberación de creatina kinasa (CK) y lactato deshidrogenasa (LDH)}

Se formaron seis grupos de 4 ratones albinos de $20 \mathrm{~g}$ de peso cada uno. Los ratones de uno de los grupos, utilizado como control, fueron inoculados con $100 \mu \mathrm{l}$ de buffer acetato de amonio 0,05 M pH 7 en el músculo gastrocnemius, mientras que al resto de roedores se les inoculó en el mismo músculo $100 \mu \mathrm{l}$ de miotoxina (60 $\mu \mathrm{g}$ de proteína). Después de $1 / 2$, $1,3,12$ y $24 \mathrm{~h}$, los ratones de los grupos respectivos, fueron anestesiados con éter colectándose inmediatamente $0,4 \mathrm{ml}$ de sangre, por punción cardiaca, los cuales se mezclaron con $40 \mu \mathrm{l}$ de citrato de sodio $3,8 \%$, luego de lo cual se centrifugó por 10 minutos a 300 x $g$ para separar el plasma.

Para medir la actividad de CK, $25 \mu \mathrm{l}$ de plasma fueron aplicados a $1 \mathrm{ml}$ del kit de CK de Pointe Scientific, preincubado a $37^{\circ} \mathrm{C}$, registrándose el incremento en la absorbancia a $340 \mathrm{~nm}$ durante 6 minutos. La actividad fue expresada en IU/L que es la cantidad de enzima que cataliza la transformación de $1 \mu \mathrm{mol}$ de substrato por minuto.

Para medir la actividad de LDH, $25 \mu \mathrm{lde}$ plasma se agregaron a $1 \mathrm{ml}$ del kit de LDH de Pointe Scientific, preincubado a $37^{\circ} \mathrm{C}$, registrándose el incremento en la absorbancia a 340 nm durante 6 minutos. La actividad fue ex- presada en IU/L que es la cantidad de enzima que cataliza la transformación de $1 \mu \mathrm{mol}$ de substrato por minuto.

\subsection{Liberación de proteínas musculares}

El daño producido por la miotoxina sobre el tejido muscular también fue evaluado por PAGE-SDS. Para esto, el músculo gastrocnemius aislado se incubó en $1 \mathrm{ml}$ de buffer fisiológico ( $\mathrm{NaCl} 6,92 \mathrm{~g} / \mathrm{L}, \mathrm{KCl}$ 0,35 g/ $\mathrm{L}, \mathrm{MgSO}_{4} 0,29 \mathrm{~g} / \mathrm{L}, \mathrm{CaCl}_{2} 0,28 \mathrm{~g} / \mathrm{L}, \mathrm{KH}_{2} \mathrm{PO}_{4}$ $0,16 \mathrm{~g} / \mathrm{L}, \mathrm{NaHCO}_{3} 2,1 \mathrm{~g} / \mathrm{L}$, glucosa $2 \mathrm{~g} / \mathrm{L} \mathrm{a} \mathrm{pH}$ $7,2)$ bajo aireación constante con $100 \mu \mathrm{g}$ de miotoxina. A diferentes tiempos $(0,10,30 \mathrm{y}$ $60 \mathrm{~min}$ ), se tomaron alícuotas de $20 \mu \mathrm{l}$ de la solución, para su análisis por PAGE-SDS (Laemmli, 1970). En el experimento control se procedió de la misma manera, pero sin miotoxina.

\subsection{Efecto histológico}

Tres grupos de 4 ratones albinos de $20 \mathrm{~g}$ de peso cada uno fueron inoculados vía i. m. con $0,1 \mathrm{ml}$ de la miotoxina $(60 \mu \mathrm{g})$ en el músculo gastrocnemius. Luego de 1, 3 y 12 horas, los animales de cada grupo se sacrificaron, y una porción del músculo fue fijado en glutaraldehído al 3\% por 2 horas y luego tratado con buffer fosfato $0,1 \mathrm{M} \mathrm{pH} 7$ por 3 horas. Posteriormente, el tejido fue deshidratado en alcohol etílico (de 30 a 100\%), y finalmente embebido en una resina Spurr para hacer cortes de 1 $\mathrm{mm}$ de espesor, que fueron teñidos con azul de toluidina al $0,5 \%$. Los daños fueron observados a través de un microscopio de luz.

\subsection{Efecto de la miotoxina sobre los ni- veles de calcio}

Con la finalidad de determinar las variaciones en los niveles de calcio del músculo esquelético por acción de la miotoxina, grupos de 4 ratones de $20 \mathrm{~g}$ de peso fueron inoculados en el músculo gastrocnemius con $50 \mu \mathrm{lde}$ miotoxina ( $5 \mu \mathrm{g} / \mathrm{g}$ de peso de ratón). Luego de 2, 4 y 6 horas, los ratones fueron sacrificados por dislocación cervical y una muestra de 60 mg de músculo fue tratado con $2 \mathrm{ml}$ de buffer Imidazol $10 \mathrm{mM}, \mathrm{pH}$ 7,1, conteniendo $\mathrm{NaCl}$ 
$140 \mathrm{mM}, \mathrm{KCl} 5 \mathrm{mM}$, digitonina $200 \mu \mathrm{g} / \mathrm{ml}$ y Antipirilazo III 0,2mM. Inmediatamente después de 8 minutos se tomó $1 \mathrm{ml}$ del sobrenadante y se leyó la diferencia en la absorbancia a 710 y $790 \mathrm{~nm}($ D 710 - $790 \mathrm{~nm})$ (Murphy et al., 1980).

Los valores de las diferencias de absorbancia 710-790 nm, fueron convertidos a nmoles de calcio, dividiéndolos entre un factor de calibración correspondiente a 0,0045 nmoles ${ }^{-1}$. Este factor fue obtenido a partir de una curva estándar para la determinación de calcio con Antipirilazo III.

Las variaciones en los niveles de calcio también se determinaron en el músculo gastrocnemius aislado. Diferentes preparaciones musculares mantenidas en una solución fisiológica $\sin \mathrm{CaCl}_{2}(\mathrm{NaCl} 6,92 \mathrm{~g} / \mathrm{L}, \mathrm{KCl} 0,35 \mathrm{~g} /$ $\mathrm{L}, \mathrm{MgSO}_{4} 0,29 \mathrm{~g} / \mathrm{L}, \mathrm{KH}_{2} \mathrm{PO}_{4} 0,16 \mathrm{~g} / \mathrm{L}, \mathrm{NaHCO}_{3}$ $2,1 \mathrm{~g} / \mathrm{L}$, glucosa $2 \mathrm{~g} / \mathrm{L} \mathrm{a} \mathrm{pH} 7,2$ ) y bajo aireación constante, fueron tratadas con $75 \mu \mathrm{l}$ de miotoxina $(100 \mu \mathrm{g})$ y a las 0,1 y 2 horas, el músculo fue colocado en $2 \mathrm{ml}$ de buffer Imidazol $10 \mathrm{mM}$, pH 7,1, conteniendo $\mathrm{NaCl} 140 \mathrm{mM}, \mathrm{KCl} 5 \mathrm{mM}$, digitonina $200 \mu \mathrm{g} / \mathrm{ml}$ y Antipirilazo III 0,2mM, para determinar los niveles de calcio de acuerdo a lo anteriormente señalado (Murphy et al., 1980).

\section{Efecto del verapamil en la acción de la miotoxina}

Con la finalidad de evaluar la mediación de los receptores de dihidropiridina, en la acción de la miotoxina, grupos de 4 ratones de $20 \mathrm{~g}$ de peso, fueron inyectados en el músculo gastrocnemius con $50 \mu \mathrm{l}$ de verapamil $(6 \mu \mathrm{g} /$ $\mathrm{g}$ de peso), y luego de 5 minutos se volvieron a inyectar con $50 \mu \mathrm{l}$ de miotoxina $(60 \mu \mathrm{g})$. Después de 1 hora, los animales fueron anestesiados con la finalidad de obtener plasma sanguíneo y medir la actividad de CK y LDH, de acuerdo a lo señalado anteriormente. Estos resultados se compararon con aquellos obtenidos en ratones del mismo peso, pero inyectados sólo con miotoxina o con buffer.

Asimismo, con la finalidad de evaluar si el verapamil era capaz de bloquear el aumento de calcio producido por la miotoxina, grupos de 4 ratones de $20 \mathrm{~g}$ fueron inyectados en el músculo

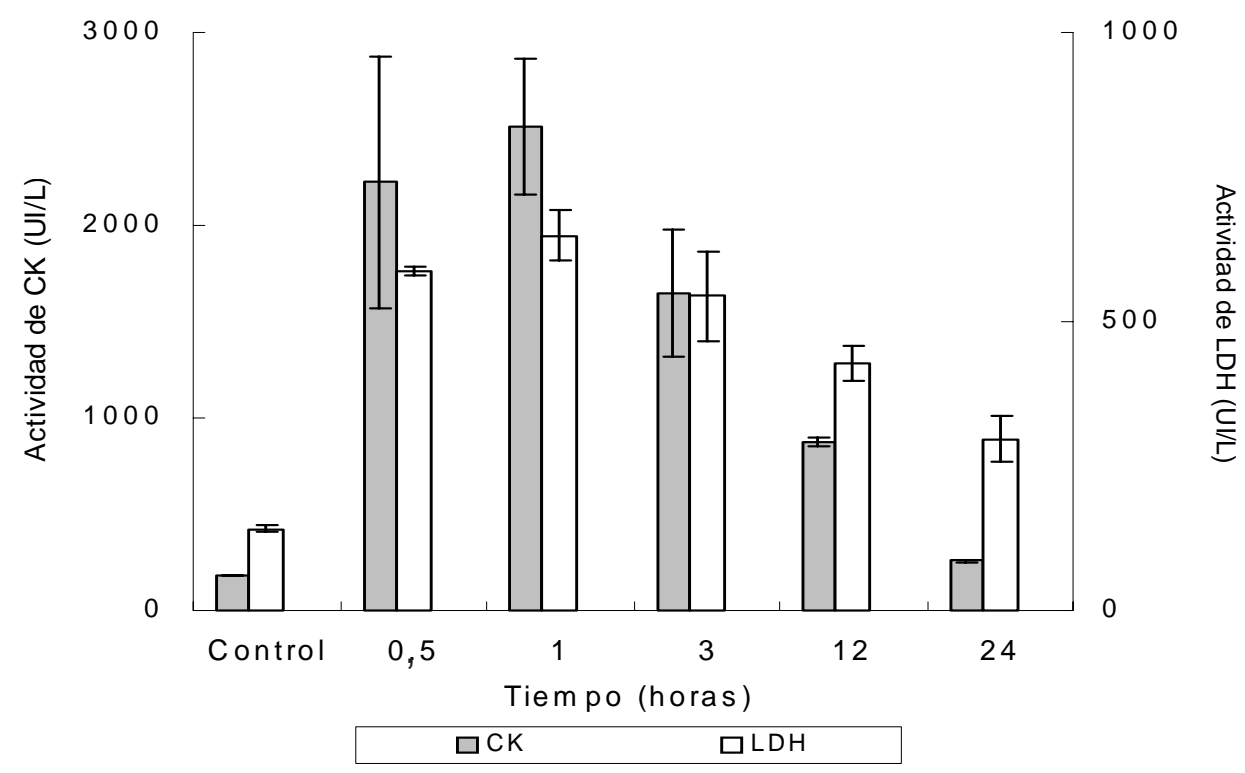

Figura 1. Las actividades de CK y LDH, en el plasma de ratones, se incrementaron por efecto de la miotoxina, desde la $1 / 2$ hora, alcanzando valores máximos luego de $1 \mathrm{~h}$ y disminuyendo a valores casi normales después de $24 \mathrm{~h}$. Los valores son el promedio \pm D. $E$. $(n=4)$. 


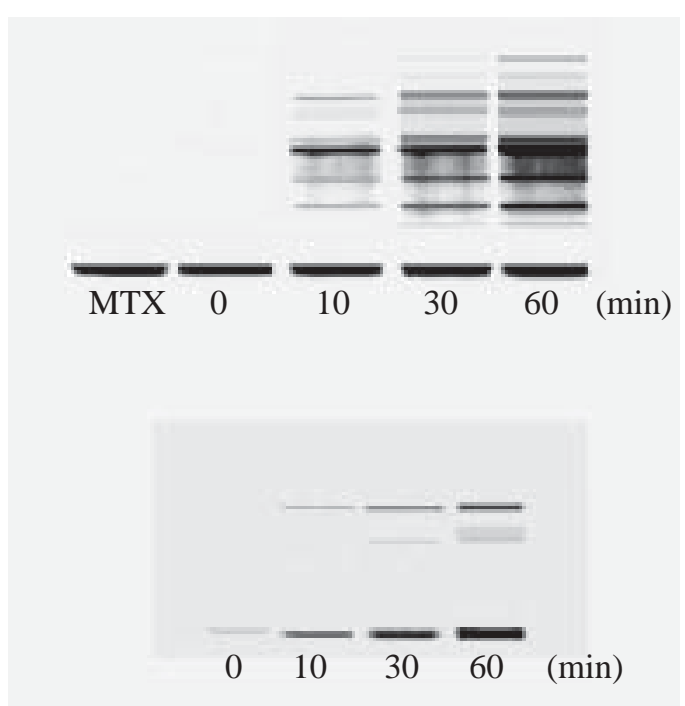

Figura 2. Evaluación por PAGE-SDS de la liberación de proteínas musculares por efecto de la miotoxina (MTX). En la parte superior se muestra la liberación de diversas proteínas musculares, a diferentes tiempos como consecuencia del daño producido por la miotoxina sobre el sarcolema, mientras que en la parte inferior se muestra la liberación de proteínas musculares en el ensayo control.

gastrocnemius con $50 \mu \mathrm{l}$ de verapamil $(6 \mu \mathrm{g} / \mathrm{g}$ de peso), y luego de 5 minutos se volvieron a inyectar con $50 \mu \mathrm{l}$ de miotoxina $(60 \mu \mathrm{g})$. Después de 4 horas, los animales fueron sacrificados para medir los niveles de calcio intramuscular con antipirilazo III (Murphy et al., 1980). Los resultados se compararon con aquellos de controles adecuados, en los que sólo se inyectó miotoxina o buffer.

\section{Resultados}

\section{Liberación de creatina kinasa y lactato deshidrogenasa}

La evaluación de los niveles de CK en el plasma de ratones tratados con miotoxina, mostraron valores elevados de esta actividad desde la 1/2 hora, alcanzando una actividad máxima de 2509,3 IU/L luego de 1 hora. Este valor en comparación al de los controles, que es de $181 \mathrm{IU} / \mathrm{L}$, representa un aumento de casi 14 veces. Igualmente los niveles de LDH en el plasma de ratones tratados con miotoxina, también se elevaron desde la 1/2 hora, alcanzando una actividad máxima de 649,3 IU/L luego de 1 hora. En los controles, la actividad de LDH mostró un valor promedio de 141,7 IU/L (Fig. 1).

\section{Liberación de proteínas musculares}

La evaluación por PAGE-SDS, del daño producido por la miotoxina sobre el músculo aislado, demostró que la miotoxina es capaz de provocar la liberación de una serie de proteínas musculares al medio de incubación. Este efecto es rápido ya que se hace evidente desde los 10 minutos de acción de la miotoxina (Fig. 2).

\section{Efecto histológico}

Los resultados de la acción miotóxica sobre el músculo gastrocnemius de ratón mostraron que la miotoxina produce desde la primera hora de acción hipercontracción de algunas fibras musculares (Fig. 3) y la aparición de "lesiones "delta". Luego de 3 horas, la desorganización de las fibras musculares aumenta, y a las 12 horas, la mionecrosis es completa de acuerdo a lo ya descrito por Pantigoso et al. (2001).

\section{Variación en los niveles de calcio}

Al evaluar los niveles de calcio intramuscular en los ratones inyectados con la miotoxina, se encontró un valor de 24,6 nmoles de $\mathrm{Ca}^{++}$, dos horas después de la inyección, alcanzándose un valor máximo de 33,3

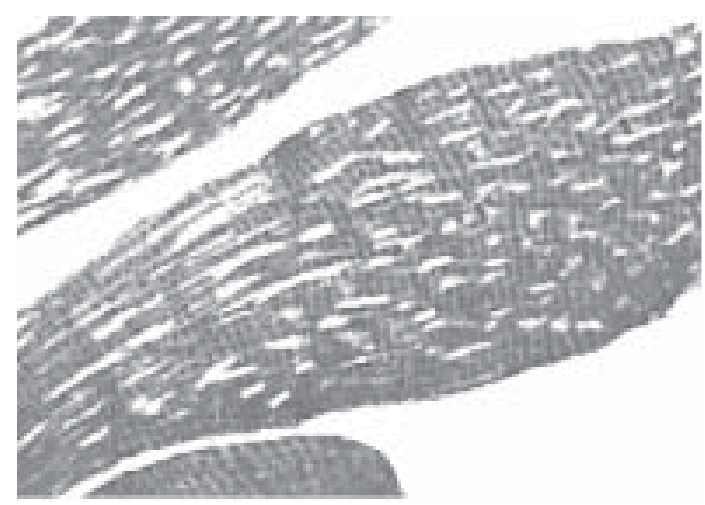

Figura 3. Observación de la hipercontracción de las fibras musculares producida por la miotoxina, durante la primera hora de acción. 


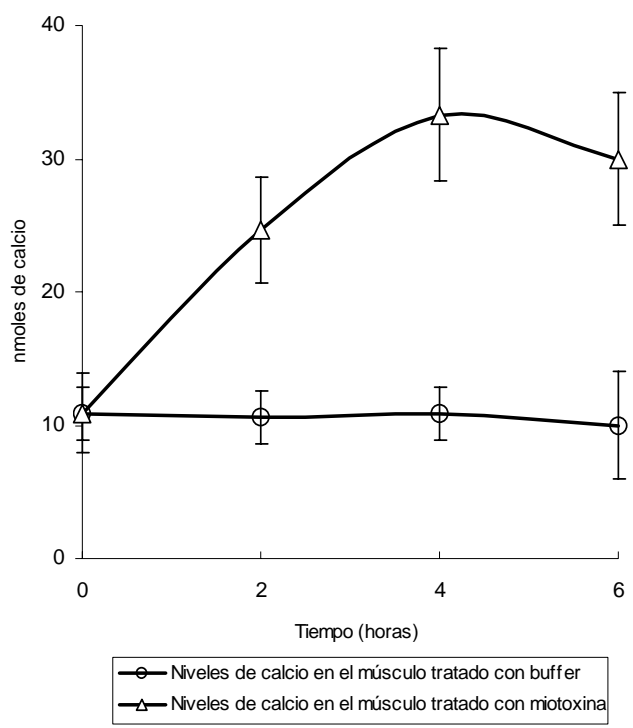

Figura 4. Variación de los niveles de calcio. La miotoxina produjo "in vivo", un aumento del calcio citosólico muscular. Los valores representan el promedio \pm D.E. $(n=4)$.

nmoles a las 4 horas, el cual representa el triple de los niveles de $\mathrm{Ca}^{++}$, encontrados en los controles (Fig. 4).

Los resultados de los ensayos "in vitro", al incubar la miotoxina con el músculo aislado en solución fisiológica sin calcio, mostraron también un aumento de la concentración de $\mathrm{Ca}^{++}$citosólico. Así, luego de 2 horas, se calcularon 46,6 nmoles de $\mathrm{Ca}^{++}$en el músculo tratado con miotoxina, mientras que en el control respectivo se determinaron 16,8 nmoles de $\mathrm{Ca}^{++}$(Fig. 5).

\section{Efecto del verapamil}

Los resultados de estos ensayos mostraron que el verapamil no afectó la capacidad de la miotoxina para ocasionar la liberación de CK y LDH (Fig. 6), ni su capacidad para incrementar el nivel de calcio citosólico (Fig. 7).

\section{Discusión}

Respecto al modo de acción de la miotoxina del veneno de $B$. brazili, los resultados sugieren que la proteína actúa probablemente a nivel de la membrana del músculo esquelético provocando su desorganización, lo cual se evidencia por la fuga de varias moléculas proteicas como las enzimas CK y LDH. La liberación de estas proteínas es rápida, ya que desde la media hora los niveles de estas enzimas se elevan considerablemente, indicando que la miotoxina induce rápidamente lesiones en la membrana, lo suficientemente grandes como para permitir el escape de CK y LDH.

La observación al microscopio, de ciertas lesiones producidas durante la primera hora de acción de la miotoxina, como por ejemplo las "lesiones delta", las cuales son lesiones en forma de cuña que representan áreas de degeneración local donde la membrana ha sido dañada, también corroboran este aspecto (Mokri and Engel, 1975).

Particularmente, los resultados indican que la miotoxina genera una liberación máxima de CK y LDH luego de $1 \mathrm{~h}$ de acción, lo cual representa un tiempo menor al encontrado con la miotoxina I de B. asper, la miotoxina II de B. moojeni y la miotoxina de B. atrox, las cuales provocan la liberación máxima de CK recién a las 3 horas (Gutiérrez et al., 1984; Lomonte et al., 1990). Sin embargo, al igual

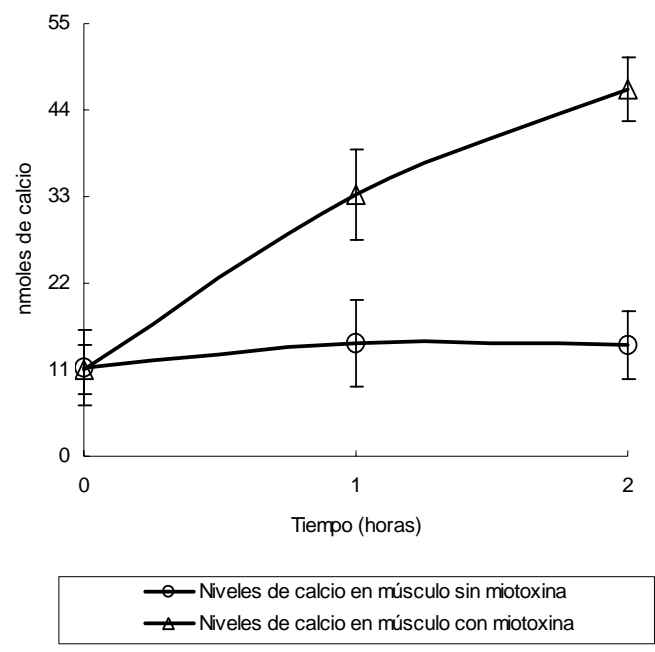

Figura 5. Variaciones de Ca++ "in vitro". La miotoxina produjo un incremento en los niveles de calcio, del músculo aislado, en relación al músculo sin tratamiento. Los valores indican el promedio $\pm D$.E. $(n=4)$. 


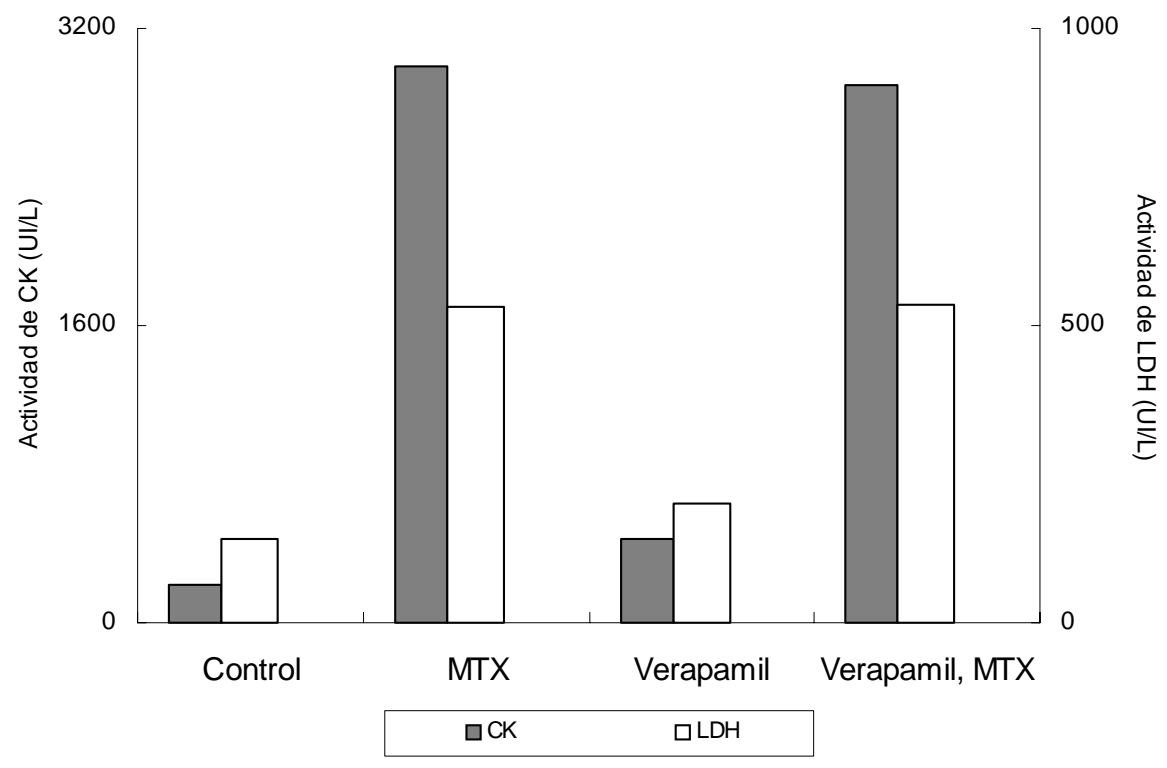

Figura 6. El verapamil no afectó la liberación de CK y LDH producida por la miotoxina $(n=4)$.

que todas las miotoxinas botrópicas estudiadas, los niveles de $\mathrm{CK}$ alcanzan valores casi normales luego de $24 \mathrm{~h}$.

Por otro lado, el análisis por PAGE-SDS, de las proteínas liberadas del músculo gastrocnemius, luego de su incubación con miotoxina, evidencian que además de CK y $\mathrm{LDH}$, muchas otras proteínas musculares también se liberan al medio, lo cual denota el daño producido por la miotoxina a nivel del sarcolema con la consecuente pérdida de moléculas proteicas. Asimismo este daño es muy rápido y dependiente del tiempo, ya que la liberación de proteínas se observa desde los 10 min y se incrementa a mayores tiempos. Sin embargo, el lugar de unión a la membrana muscular de todas las miotoxinas de venenos de serpientes permanece aún sin ser conocido, aunque se reconoce que pueden estar involucrados determinados componentes de la membrana de la célula muscular que determinarían la especificidad de unión al sarcolema y la falta de acción sobre otras membranas celulares como, por ejemplo, la de glóbulos rojos, lo cual ha sido verificado también con la miotoxina de $B$.

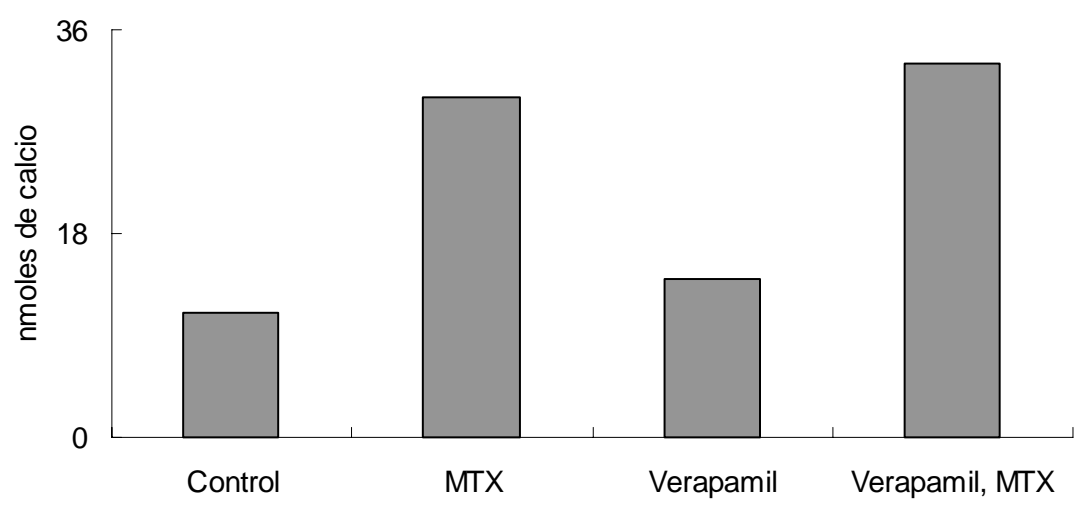

Figura 7. El incremento de calcio citosólico, producido por la miotoxina, no fue atenuado por el verapamil. 
brazili (Pantigoso et al., 2001). Por otro lado la falta de actividad de fosfolipasa de la miotoxina estudiada, corrobora el concepto de que el daño en la fibra muscular, no es a través de la hidrólisis directa de fosfolípidos de membrana (Gutiérrez et al., 1989).

Un aspecto interesante que se ha hallado en este trabajo, es el hecho de que la miotoxina es capaz de incrementar tanto in vivo como in vitro, los niveles de calcio citosólico de la fibra muscular.

Para esto, tal como se describió en Material y Métodos, el músculo fue tratado con digitonina a fin de permeabilizar el sarcolema de las fibras musculares y permitir que los iones $\mathrm{Ca}^{++}$sean liberados para su detección con Antipirilazo III. Con este tratamiento, el calcio liberado y detectado es básicamente citosólico. De este modo, se ha encontrado in vivo, que la miotoxina es capaz de incrementar progresivamente los niveles de $\mathrm{Ca}^{++}$, hasta triplicar, luego de $4 \mathrm{~h}$, los valores de los controles. Los ensayos in vitro igualmente permiten evidenciar que el $\mathrm{Ca}^{++}$se incrementa hasta casi 3 veces, luego de 2 horas, con relación a los controles. Este aumento de calcio sarcoplasmático, producido por la miotoxina, es importante inicialmente, porque permite explicar la hipercontracción observada en las fibras musculares durante la primera hora de acción.

Sin embargo, el incremento del $\mathrm{Ca}^{++}$ citosólico, plantea una interrogante adicional en relación a la manera en que la miotoxina produce este aumento. Al respecto, es necesario precisar que la fibra muscular en reposo contiene aproximadamente $0,2 \mu \mathrm{M}$ de $\mathrm{Ca}^{++} \mathrm{li}$ bre en el citosol, pero cuando entra en actividad, por ejemplo durante la contracción, este valor se eleva considerablemente. Para lograr esto, la fibra muscular dispone de reservas internas de $\mathrm{Ca}^{++}$almacenadas en el lumen del retículo sarcoplasmático que pueden ser utilizadas vía canales de calcio que se ubican en la membrana de este retículo y que son de dos tipos: los receptores de ryanodine y los recep- tores de inositol trifosfato $\left(\mathrm{IP}_{3}\right)$. En particular, los receptores de $\mathrm{IP}_{3}$ operan cuando a nivel de la membrana celular, se activa una fosfolipasa c que al actuar sobre el fosfatidil 1,4 bi fosfato, genera $\mathrm{IP}_{3}$, el cual se une a sus receptores del retículo sarcoplasmático provocando la liberación de calcio. Otra fuente de calcio, lo constituye el $\mathrm{Ca}^{++}$extracelular que puede ingresar a la fibra muscular a través de otro tipo de canales ubicados en los túbulos T $y$ que se denominan receptores de dihidropiridina.

Por otro lado, una bomba de calcio $\left(\mathrm{Ca}^{++}-\right.$ ATPasa) ubicada en la membrana del retículo sarcoplasmático, se encarga de volver a secuestrar los iones $\mathrm{Ca}^{++}$en el lumen del retículo sarcoplasmático, y retornar la concentración del calcio citosólico a valores normales.

De acuerdo a lo anteriormente señalado, el aumento de $\mathrm{Ca}^{++}$producido por la miotoxina, luego de su interacción con el sarcolema, podría deberse a una activación de los receptores de dihidropiridina o de los receptores de $\mathrm{IP}_{3}$, vía activación de fosfolipasa c. La alternativa de que, in vivo, la miotoxina pueda activar directamente a los receptores de ryanodine o inactivar a la bomba de $\mathrm{Ca}^{++}$(lo que también explicaría el aumento de $\mathrm{Ca}^{++}$), es un aspecto que actualmente no es aceptado, ya que para que esto ocurra, la miotoxina debería ser previamente internalizada en la fibra muscular, lo cual hasta la fecha no ha encontrado apoyo experimental.

Pues bien, los ensayos realizados in vivo empleando verapamil, el cual es un bloqueador de los receptores de dihidropiridina, muestran que la capacidad de la miotoxina para elevar el $\mathrm{Ca}^{++}$citosólico y ocasionar la liberación de $\mathrm{CK}$ y LDH, permanecen inalterables, lo cual indicaría que la elevación de calcio, producido por la miotoxina, no es a través de estos receptores. Además, los ensayos realizados in vitro, refuerzan también la imposibilidad de que el aumento de calcio se deba al ingreso de calcio externo, ya que en estos ensayos el medio de incubación que se empleó carecía 
de cloruro de calcio. Por lo tanto, resulta claro que la miotoxina no incrementa el $\mathrm{Ca}^{++}$ citosólico a través de los receptores de dihidropiridina.

La posibilidad de que el aumento de $\mathrm{Ca}^{++}$ se deba a una activación de la fosfolipasa c de membrana, luego de la unión de la miotoxina, tal como ha sido propuesto para las cardiotoxinas (Fletcher and Jiang, 1993), es un aspecto para el que, desafortunadamente, no tenemos ninguna evidencia experimental.

Sin embargo, la elevación del calcio también podría ser una consecuencia mas general del daño en la integridad del sarcolema, producida por la miotoxina, tal como ha sido demostrado con algunas sustancias, que al alterar la integridad de la membrana plasmática, ocasionan un aumento del $\mathrm{Ca}^{++}$citosólico (Morena and Kinneb, 1998).

De este modo, luego del daño del sarcolema producido por la miotoxina, el aumento del calcio en la célula muscular sería un aspecto particularmente importante ya que explicaría no solo la hipercontracción observada, sino además podría conducir a la activación de fosfolipasas y proteasas endógenas dependientes de calcio, que producirían finalmente la degeneración y mionecrosis.

En general ha sido propuesto que un incremento del calcio citosólico es un paso crítico de la muerte celular en una amplia variedad de condiciones patológicas (Trump et al., 1982).

\section{Literatura citada}

Fletcher, J. and Jiang, M-S. 1993. Possible mechanisms of action of cobra ake venom cardiotoxins and bee venom mellitin. Toxicon 31 (6) : 669-695.

Gutiérrez, J.; Ownby, C. and Odell, G. 1984. Isolation of a Miotoxin from Bothrops asper venom: Partial Characterization and action on skeletal muscle. Toxicon, 22, (1) : 115-128.

Gutiérrez, J.; Lomonte, B. and Cerdas, L. 1986. Isolation and partial characterization of a myotoxin from the venom of the snake Bothrops nummifer. Toxicon 24 ( 9) : 885-894.

Gutiérrez, J.; Chávez, F.; Gene, J.; Lomonte, B.; Camacho, Z. and Schosinski, K. 1989. Myonecrosis induced in mice by a basic myotoxin isolated from the venom of the snake Bothrops nummifer (jumping viper) from Costa Rica, Toxicon 27 : 735-745.

Gutiérrez, J.; and Lomonte, B. 1997. Phospholipase A $_{2}$ Miotoxins from Bothrops snake venoms. In: Venom Phospholipase A Enzymes: Structure, Function, and Mechanism. (Ed. R. Manjunatha Kini). John Wiley and Sons. 321-352.

Homsi-Brandeburgo, M.; Queiroz, L.; Santo-Neto, H.; Rodrigues-Simioni, L. and Giglio, J. 1988. Fractionation of Bothrops jararacussu snake venom: Partial chemical characterization and biological activity of bothropstoxin. Toxicon $26: 615-627$.

Houssay, B. 1930. Classification des actions des venims de serpents sur l'organisme animal. C.R. Soc. Biológicas. Paris 105 : 308-310.

Kaiser, E. and Michl, H. 1958. In: Die Biochemie der tierischen Gifte, 1st ed., pp. 134-222. Vienna. Deuticke.

Kellaway, C. 1939. Animal Poisons. Ann. Rev. Biochem. $8: 541-556$.

Kurashigue, S.; Hara, Y.; Kawakami, M. and Mitsuhashi, S. 1966. Studies on Habu snake venom. VII. Heat-stable myolitic factor and development of its activity by addition of phospholipase A. Japan J. Microbiol. 10 : 23-31.

Laemmli, U. 1970. Cleavage of structural proteins during the assembly of the head of bacteriophage T4. Nature 227 : 680-685.

Lomonte, B.; Gutiérrez, J.; Furtado, M.; Otero, R.; Rosso, J-P.; Vargas, O.; Carmona, E. and Rovira, M. 1990. Isolation of basic myotoxins from Bothrops moojeni and Bothrops atrox snake venoms. Toxicon 28 (10) : 137-1146.

Lowry, O.; Rosebrough, N.; Farr, A. and Randall, R. 1951. Protein measurement with the Folin phenol reagent. J. Biol. Chem. 193 : 265-275.

Maeno, H.; Mitsuhashi, S.; Okonogi, T.; Hoshi, S. and Homma, M. 1962. Studies on Habu snake venom. V. Myolisis caused by phospholipase A in Habu snake venom. Japan. J. Exp. Med. $32: 55-64$.

Mokri, B. and Engel, A. 1975. Duchenne dystrophy: electron microscopic findings pointing to a basic or early abnormality in the plasma membrane of the muscle fiber. Neurology $25: 1111$.

Morena, F. and Kinneb, R. 1998. Cellular calcium in health and disease. Biochimica et Biophysica Acta (BBA)/Molecular basis of disease. 1406 : 127-151.

Murphy, E.; Coll, K.; Rich, T. and Williamson, J. 1980. Hormonal effects on calcium homeostasis in isolated hepatocytes. J. Biol. Chem. 255 : 6600.

Ownby, C. 1998. Structure, function and biophysical aspects of the myotoxins from snake venoms. J.Toxicol. Toxin Rev. 17 : 213-239. 
Ownby, C.; Cameron, D. and Tu, A. 1976. Isolation of myotoxic component from rattlesnake (Crotalus viridis viridis) venom. Electron microscopic analysis of muscle damage. Amer. J. Pathol. 85 : 149-166.

Ownby, C.; Selistre De Araujo, H.; White, S. and Fletcher, J. 1999. Lysine 49 phospholipase $A_{2}$ proteins. Toxicon $37: 411-445$.

Pantigoso, C.; Escobar, E. y Yarlequé, A. 2001. Aislamiento y caracterización de una miotoxina del veneno de la serpiente Bothrops brazili (Ophidia: Viperidae). Rev. Peru. de Biol. 8 (2) : 136-148.

Porges, N. 1953. Snake venoms, their biochemistry and mode of action. Science, $117: 47-51$.

Reid, H. 1964. Cobra-bites. Brit. Med. J. 2 : 540-545.

Rosenfeld, G. 1971. Symptomatology, pathology, and treatment of snake bites in South America. In: Bücherl, W., Buckley, E., Deulofen, V. (Eds.): Venomous Animals and their venoms, Vol. II, pp. 345-384. New York: Academic.
Sarkar, N. and Devi, A. 1968. Enzymes in snake venoms. In: Bücherl, W., Buckley, E., Deulofen, V. (Eds). Venomous Animals and their venoms. Vol. I. : 167-216. New York. Academic.

Tu, A.; Homma, M. and Hong, B. 1969. Hemorrhagic, myonecrotic, thrombotic, and proteolytic activities of viper venoms. Toxicon $6: 175-178$.

Trump, B.; Berzesky and Cowley, R. 1982. The cellular and subcellular characteristics of acute and chronic injury with emphasis on the role of calcium. In: Pathophysiology of shock, anoxia and ischemia, P.G. (Cowley, R. and Trump, B., Eds.). Williams and Wilkins. Baltimore. 6-46.

Volpe, P.; Damiani, E.; Maurer, A. and Tu, A. 1986. Interaction of Myotoxin a with the $\mathrm{Ca}^{2+}$-ATPase of Skeletal Muscle Sarcoplasmic Reticulum, Arch. Biochem. Biophys. 246, (1) : 90-97.

Yudkowsky, M.; Beech, J. and Fletcher, J. 1994. Myotoxin a reduces the threshold for calciuminduced calcium release in skeletal muscle. Toxicon $32:$ 273-278.

Zeller, E. 1948. Enzymes of snake venoms and their biological significance. Advances in enzymology. $8: 459-495$. 